\title{
Application of Solution Protein Chemistry to Biotechnology
}

\author{
(R. L. Lundblad, CRC, Taylor\&Francis Group, Boca Raton, FL, USA, 442 p., 2009, \$169.95)
}

DOI: $10.1134 / \mathrm{S} 0006297910060155$

This book was written by a well known expert in protein chemistry and biochemistry, Professor Roger Lundblad, the author of several monographs in the field of proteins and Editor-in-Chief of the Internet Journal of Genomics and Proteomics.

The book consists of 10 chapters, subject index, and bibliography to each chapter.

Chapter 1 is an introduction to the solution chemistry of proteins. It presents brief summaries about protein chemical modifications and focuses on reagents for the chemical modification of proteins and other biological macromolecules. This chapter also includes numerous methods for modification of proteins by various chemical reactions of different amino acid groups in proteins. There are number of chemical modifications of proteins that can markedly influence function. Such in vivo chemical modifications include cotranslational and posttranslational reactions, as well as sulfation, methylation, and phosphorylation. The chapter is very informative and contains around 700 references.

Chapter 2 highlights data about the application of solution protein chemistry to the study of biopharmaceutical conformations. The characterization of protein therapeutics is a critical part of the drug development and approval process. A special part of this chapter deals with chemical structure, biological activity, and conformational analysis of proteins.

Chapter 3 is devoted to chemistry of the attachment of proteins and peptides to solid surfaces. The chapter contains data about various solid-phase matrices and chemical approaches for attachment of protein samples to these matrices.
Chapter 4 deals with protein conjugates including albumin, antibody-protein, antibody-drug, proteincarbohydrate, and polyethylene glycol bioconjugates. One part of this chapter is devoted to characterization of polysaccharide conjugates.

Chapter 5 discusses protein hydrogels. Proteins and peptides can be enclosed with hydrogels or covalently linked to the hydrogel polymers by chemistries described in the previous chapters of this book (chapters 1 and 3). Collagen and gelatin are also described as important components for preparation of hydrogels.

Chapter 6 summarizes preparation of adhesives, glues, and sealants. Collagen, albumin, and fibrinogen are used for tissue solder material.

Chapter 7 deals with protein drug delivery. Peptide drug applications include peptidomimetics and peptidebased prodrugs.

Chapter 8 discusses the application of solution protein chemistry to proteomics.

Chapter 9 describes chemical modification to produce biopharmaceutical products. The major attention is directed to characterization of chemical approaches to make proteins with better biological activity, storage stability, and increased circulatory half-life.

Chapter 10 describes proteins as important components of food and agriculture.

The book is a very valuable source for specialists interested in various aspects of proteins-from physicians to biochemists, molecular biologists, geneticists, and biotechnologists. There is no doubt that this book will be very useful for medical schools and universities students and their teachers. 